\title{
A New Year, A New Issue and Evolution of the Canadian Journal of Neurological Sciences
}

Can. J. Neurol. Sci. 2002; 29: 1-3

It is with delight that I introduce the first Canadian Journal of Neurological Sciences (CJNS) issue of 2002. This issue marks progress, evolution and innovation at CJNS.

My first message is to introduce new members of our Editorial Board, both from within Canada and outside of Canada. These new members bring particular expertise to the journal and will serve us well. At the same time, I offer thanks and appreciation on behalf of CJNS and its readers, for the distinguished editorial service of several members that are rotating off of the Editorial Board. CJNS is deeply indebted to your work and thoughtfulness (see listing on page 3). Similar deep thanks and appreciation to Dr. Warren Mason who has served CJNS as a dedicated book editor since 1997. I would like to announce that Dr. Chris White will now be assuming this role for CJNS and we look forward to his input. In this issue, I also wish to thank the work of our ad hoc reviewers, also listed. Without their work, we would not have a peer-reviewed journal. I should point out that over the past year we have made a substantial change in how our manuscripts are reviewed, and we are now only allowing referees a short period to turn the papers around (three weeks). It is remarkable that there have been relatively few complaints from our reviewers about this accelerated demand on their time, and most have greeted this change as a significant improvement in how we handle our submitted manuscripts. Our Journal office and staff played a major role in developing this new approach.

Our submission rates and impact factor have both climbed. Within the next six months, we should see full text access of all manuscripts in the CJNS available online to members of the Canadian Congress of Neurological Sciences (CCNS) or subscribers to CJNS. Over the last two years this has been available for two papers per issue and all abstracts. The worldwide direction of electronic publication has been evolving very rapidly and uncertainly, and predicting the best way to respond has not been easy. Ms. Sally Gregg, the Managing Director of CJNS and Sue Impey, Production Editor of the Journal have spent countless hours researching a variety of electronic venues for CJNS that would best serve its readers and the Canadian Neurosciences community at large. I think all of these constituencies will be very satisfied with the results. In a related vein, I am also delighted to report that Dr. Daniel Keene has become the new "Electronic Editor" for CCNS. His expertise will serve us well.

Areas of continued development include the need for us to capture a yet larger proportion of both Clinical and Basic
Neurosciences research generated from this country and abroad. I think all prospective authors should consider CJNS first. As the interest in and value of our journal progress, the wisdom of having chosen our journal over others will be obvious. I can attest to the fact that our journal has had an excellent reputation outside of this country. With further increases in the submission rate, we will be able to increase the number of issues per year. In turn, speedy publication of your work without diluting the quality of CJNS will be in the interest of all of our authors. Dilution can be a problem with journals that expand too rapidly. We would like publication in CJNS to continue to be viewed as a significant academic accomplishment.

In this issue, we introduce a number of interesting new items. A broad group of Editors of Clinical Neuroscience journals have agreed to publish a common Editorial entitled "Reporting Clinical Trials: Full Access to all the Data". The publication of this editorial appears in this issue. I think the piece speaks for itself and it represents a significant advance in how clinical trials data will be handled. In a similar vein, Editors of a broad group of Canadian Medical Journals met in Ottawa on November 5, 2001, in a workshop sponsored by the Canadian Medical Association Journal. The highlight of the meeting was Ethics in Journal Publishing. Participants in this workshop have also signed on to the new standards for reporting clinical trials and these will be incorporated into a revised "Uniform Requirements for Manuscripts Submitted to Biomedical Journals", a document developed by the international committee of Medical Journal Editors. Additional byproducts of the meeting in Ottawa were decisions to create a database on ethical issues in medical publications (these include such issues as duplicate research submissions, fraudulent data etc.), and an agreement to continue the interaction among Canadian medical editors. It is a very positive development. In the spirit of these guidelines and discussions, as Editor-in-Chief of CJNS, I enclose at the bottom of this editorial, a disclosure about my own interactions with industry. This should become the standard for all authors, in addition to the already signed waivers on conflict of interest that we require for both authors and reviewers.

I am pleased to introduce an additional innovation in CJNS, a publication exchange with the Neurological Journal of Southeast Asia. This is an interaction recently developed by one of our former editors, Dr. Robert Lee. Canadians have become global travellers and Canada has become home for individuals who have come here from around the globe. It is of significant benefit to Canadians to understand the neurological problems that exist in a 
very different constituency. Our agreement with the Neurological Journal of Southeast Asia is that we have the opportunity of periodically republishing one of their papers of interest to CJNS while they choose one of ours. In this issue, I introduce the first such exchange with a paper on Nipah Encephalitis.

Please continue to send us your work. We need more submissions in the area of Basic Neurosciences (a highly productive area in Canada) and we would dearly like to see more Neuropathological Conferences. To that purpose, I have specifically re-invited all Program Directors across the country to send them to us. As stated before, this venue for reporting interesting neurological problems, to my mind, would take priority over single case reports and we strongly encourage senior Neurology, Neurosurgery, Paediatric Neurosciences and Neuropathology residents to submit these to us. I am also very interested in feedback from you, the readers. We need articles on controversial topics in the form of debates and we welcome letters commenting on published material. Keep them coming.

\section{Douglas W. Zochodne}

\section{EDITOR-IN-ChIEF DisClosure}

Dr. Douglas W Zochodne has served as an expert paid consultant on occasion for Amgen and Roche and has ongoing agreements to consult with Cromedica, a trials sponsor and Aegera Therapeutics, a biotech company. Manuscripts related to these groups would be handled by an Associate Editor of CJNS. Dr. Zochodne otherwise has no additional financial relationships with members of the pharmaceutical or biomedical industry that would constitute a conflict of interest in the reviewing and disposition of manuscripts. 


\section{Thank you to our Reviewers}

We are indebted to the expert referees who have reviewed submission to the Canadian Journal of Neurological Sciences in 2001 (names in bold reviewed five or more papers). Their thoughtfulness and expertise has served our journal well. I wish to thank the following members of the Editorial board who are now rotating off: Drs. Andrew Eisen, Anthony Hakim, Mark Morrow and C. Warren Olanow. At the same time I welcome Drs. Richard Desbiens, Hans-Peter Hartung, Jack Jhamandas, Michael Shevell and Sam Wiebe.

Douglas W. Zochodne Editor-in-Chief

Coleen Adams
Fred Anderman
Lee Ang
Jack Antel*
Zohar Argov
P.A. Barber
Richard Barohn
Werner Becker
Paul Bedard
Andre Bellavance
Timothy J. Benstead
Jeff Blackmer
Warren Blume
Julien Bogousslavsk
Charles Bolton
Christopher Bozeck
Vera Bril
Michael H. Brooke
Mark J. Brown
Keith Brownell
Donald G. Brunet
Joseph Bruni
Alastair Buchan
Gregory Cairncross*
Peter Camfield
Neil Cashman
Arthur Clark
Paul Cooper
Husam Darwish
H. Darwish
Jasper Daube
Andrew Demchuk
Henry Dinsdale
Christopher Doig
Joseph Dooley
Christopher Dowd
James Drake
P. James Dyck
John Edmeads
J. Eggermont

M. George Elleker

Jean-Pierre Farmer

Thomas Feasby

Michael Fehlings

Howard Feldman

Eva Feldman

Howard Feldman

J. Max Findlay*

Ian Fleetwood

William Fletcher

Peter Forsyth

David Fortin

Serge Gauthier

Marek J. Gawel

David George

Peter Goadsby

Alan Goodridge

Kevin Gordon

Alan Guberman

Abhijit Guha

Mark Guttman

Neil Hagen

Angelika Hahn

Hans-Peter Hartung

Michael Hill

Matthew J. Hogan

Renn Holness*

D.C.N. Howse

William $\mathrm{Hu}$

Mark Hudon

R. John Hurlbert

Alan Jackson*

Gregor Jason

Jack H. Jhamandas

Michael Jones

Michael Kalichman

Andrew Kertesz

Barry Kimberley

Andrew Kirk

Douglas Kondziolka*
Charles Krieger

Anne-Louise LaFonta

Terrence D. Lagerlu

Robert G. Lee

Donald H. Lee

Stan Leung

Richard Lipton

William J. Logan

Stephen Lownie

Samuel Ludwin

David R. MacDonald

Gregg MacLean

Gordon Mackie

Wayne Martin

Charles Maxner

Jeannette McGlone

Stephen McKenzie

Michel Melanson

Tilak Mendis

Vivek Mehta

Luanne M. Metz

W. Morrish

S. Terence Myles*

Robert F. Nelson

Michael W. Nicolle

John H. Noseworthy*

Brian O'Neill

C. Warren Olanow*

Andrew Parrent

David Pelz

Ronald Petersen

Steven Phillips

Neelan Pillay

Christopher Power

Allan Purdy

David Ramsay*

Neil Raskin

N. Barry Rewcastle

Peter Richardson*

Karen Rimmer
Gregory Ross

James Russell

Mark Sadler

Dessa Sadovnick

Jacob H. Schneiderm

Shashi Seshia*

Robert Sevick

Michael I. Shevell

Ashfaq Shuaib

Stephen Silberstein

Andre Smith

J. David Spence

Paul Steinbok*

B.J. Stern

A. Jon Stoess1*

Michael Strong

Oksana Suchowersky

Mecheri Sundaram

Garnette Sutherland

Philip Teal

Jeanne Teitelbaum

John Turnbull

Ian Turnbull

Valerie Verge

Harry Vinters

Ananda Weerasuriya

Brian Weinshenker

Samuel Weiss

Richard Wennberg

Wayne Weston

Wayne Weston

Chris White

Samuel Wiebe

David Wiebers

E. Wijdicks

Robert A. Willinsky

Elaine Wirrell

Jerome Yager

W. Yong

G. Bryan Young

* Editorial Board 